\title{
Upregulation of microRNA-16 alters the response to inhaled $\beta$-agonists in patients with asthma though modulating expression of ADRB2
}

\author{
BO YU ${ }^{1}$, LUSU YAO ${ }^{2}$, CUIQIAO LIU ${ }^{2}$, LINA TANG ${ }^{2}$ and TAO XING ${ }^{2}$ \\ Departments of ${ }^{1}$ Respiratory Medicine and ${ }^{2}$ Neurological Intensive Care Unit, \\ Liaocheng People's Hospital, Liaocheng, Shandong 252000, P.R. China
}

Received April 4, 2017; Accepted October 15, 2018

DOI: $10.3892 / \mathrm{mmr} .2019 .10097$

\begin{abstract}
MicroRNAs (miRNAs) are non-coding RNAs of $\sim 22$ nucleotides in length, which serve an important role in numerous diseases. Asthma is a chronic airway inflammatory disease, which is the most common chronic disease among children. The role of miRNA (miR)-16 in asthma is unclear. The objective of the present study was to examine the underlying molecular mechanism of the involvement of miR-16 in asthma. A total of 72 volunteers diagnosed with asthma consented to participate in the study, of whom 52 participants were identified to be sensitive to salmeterol and 20 participants were identified to be resistant to salmeterol. Receiver operating characteristic (ROC) curve analysis was performed to compare the expression levels of serum miR-16 between the sensitive and resistant groups, and to confirm the association between the expression level of serum miR-16 and forced expiratory volume in $1 \mathrm{sec}$ (FEV1). In silico analysis, a luciferase assay, reverse transcription-quantitative polymerase chain reaction analysis and western blotting were performed to elucidate the molecular mechanism underlying the role of miR-16 in asthma. ROC results demonstrated that the serum miR-16 level may function as a biomarker to predict the response to salmeterol therapy, and the miR-16 expression level displayed a significant negative correlation with FEV1. According to the in silico analysis, adrenoreceptor $\beta-2$ (ADRB2) was a direct target of miR-16, and it was further confirmed by luciferase assay that $25 \mathrm{nM}$ miR-16 mimic had an inhibitory effect on the luciferase activity of the wild-type ADRB2 3' untranslated region (UTR); the inhibitory effect on the luciferase activity of the wild-type ADRB2 3'UTR was stronger with $50 \mathrm{nM}$ miR-16 mimic, and strongest with $75 \mathrm{nM}$ miR-16 mimic, whereas the luciferase activity of the mutant ADRB2 3'UTR in cells was
\end{abstract}

Correspondence to: Professor Lusu Yao, Department of Neurological Intensive Care Unit, Liaocheng People's Hospital, 67 Dongchang Xi Road, Liaocheng, Shandong 252000, P.R. China E-mail: asthmardb2@126.com

Key words: microRNA-16, $\beta$-agonists, asthma, adrenoreceptor $\beta-2$ similar following treatment with $0,25,50$ or $75 \mathrm{nM}$ miR-16 mimic. miR-16 reduced the mRNA and protein expression levels of ADRB2 in a dose-dependent manner. These results identified that miR-16 may be used as a predictive biomarker of therapeutic response in asthma.

\section{Introduction}

Chronic obstructive pulmonary disease and asthma are chronic inflammatory disorders of the airways that trigger airflow limitation. The onset of asthma generally occurs in childhood, and in these cases is frequently associated with allergies. The patient may recover and experience a relapse in adulthood, or symptoms may be present throughout adolescence to adult life (1). In addition, asthma may recur at any age, mediated by a serious respiratory tract infection in certain cases. Asthma is characterized by shortness of breath, chest pressure, and variable and intermittent wheezing (2). The application of corticosteroids is recommended to regulate inflammation of the airway in chronic asthma, according to current guidelines (3). However, clinical studies reveal that sensitivities to the treatment vary largely in different individuals, with up to $25 \%$ of patients exhibiting no response to oral corticosteroids, and up to $45 \%$ of patients exhibiting a suboptimal response to inhaled corticosteroids $(4,5)$. Airway inflammation is observed in these corticosteroid-resistant (CR) patients, which leads to the serious asthma phenotype frequently found in these patients (6). For those patients with a variant corticosteroid response, switching to other treatments is required to enhance asthma control (7). Chronic airway inflammation in $\mathrm{CR}$ asthma is induced by the resistance to corticosteroids of lung macrophages (8).

$\beta-2$ adrenergic receptor ( $\beta 2 \mathrm{AR})$ has been identified to have an important role in the occurrence of asthma. In 1968, Kunos and Szentivanyi (9) suggested that partial $\beta$-adrenergic blockade causes bronchial hyperresponsiveness. This hypothesis was derived from evidence indicating enhanced $\beta 2 \mathrm{AR}$ downregulation, reduced $\beta 2 \mathrm{AR}$ density and decreased $\beta$-adrenergic responses in human airway smooth muscle cells and lymphocytes originating from asthmatics, when compared with controls (10). The $\beta-2$ adrenergic receptor has been mapped to chromosome $5 q 31-33$, an area identified by a range 
of genome-wide and regional investigations to be harboring an asthma or atopy-predisposition locus (11). Considering the correlation between bronchial hyperresponsiveness and the 5q31-33 locus, $\beta 2$ AR may be a potential gene for asthma (12).

Representing a class of ubiquitous, single-stranded non-coding RNAs, microRNAs (miRNAs) consist of 19-22 nucleotides. miRNAs bind to the $3^{\prime}$ untranslated regions (3'UTRs) of mRNAs in mammalian cells, largely via incomplete base-pairing, to post-transcriptionally suppress gene translation and hence decrease the expression of target genes (13). miRNAs have a regulatory role in numerous biological processes, including stress, cell development and differentiation (14).

Mouse and human models have been established to investigate the effect of miRNAs in the pathogenesis of asthma. To date, asthmatic patients have been identified to have differential expression of $>100$ miRNAs when compared with normal healthy subjects (15). Nevertheless, different studies frequently conflict with respect to the direction of differential expression of miRNAs in asthma (16). A comparison of 16 asthmatics to 12 healthy controls identified that miRNA (miR)-221 was discovered to be increased (17). The study of Burger et al (18) revealed that decreased airway inflammation may be triggered by blocking miR-221 in a mouse asthma model induced by ovalbumin, demonstrating the function of miR-221 in asthma. T cells have been the focus in the majority of investigations on miRNAs in the blood for asthma risk. For instance, elevated expression of miR-155 was observed in bronchial epithelial cells when seven patients with asthma were compared with seven healthy subjects (16); while asthmatic patients had lower expression of miR-155 expression in cluster of differentiation $4^{+} \mathrm{T}$ cells, a greater reduction was observed when the disease severity was increased from mild to severe asthma (19).

It has been previously reported that miR-16 is differentially expressed in blood collected from the disease, and dysregulation of adrenoreceptor $\beta-2$ (ADRB2) has also been reported to be involved in the molecular mechanism underlying the control of smooth muscle cell contraction (20-22). By searching the online miRNA database miRanda, it was identified that ADRB2 is a virtual target of miR-16. In the present study, ADRB2 was validated as a target of miR-16, and the involvement of miR-16 and ADRB2 in the development of the disease was verified.

\section{Materials and methods}

Subjects. The present study was conducted according to the Declaration of Helsinki. A total of 72 participants between January 2017 and December 2017 were enrolled in the study at the Department of Respiratory Medicine, Liaocheng People's Hospital (Liaocheng, China), and all of them were diagnosed with asthma. Among the 72 participants, 52 asthmatic participants were sensitive to salmeterol, and 20 asthmatic participants were resistant to salmeterol. Participants who had had medical disorders of the upper and lower respiratory tract within the past 3 months, diabetes mellitus, chronic heart or lung disease, immunodeficiency or tumors were excluded from the study. Moreover, subjects receiving systemic corticosteroids or antihistamines within 1 month prior to the research were also excluded. The institutional Ethics and Research Committees of Liaocheng People's Hospital approved the protocol of the present study. The patients signed informed consent forms for participation in the study.

Pulmonary artery smooth muscle cell (PASMC) isolation. Blood vessels were isolated from the pulmonary artery and mechanically cut into small pieces in a cold buffer containing $127 \mathrm{mM} \mathrm{NaCl}, 5.9 \mathrm{mM} \mathrm{KCl}, 1.2 \mathrm{mM} \mathrm{MgCl}_{2}, 2.4 \mathrm{mM} \mathrm{CaCl}_{2}$, $1.8 \mathrm{mM}$ glucose and $10 \mathrm{mM}$ HEPES adjusted to $\mathrm{pH} 7.4$. Enzymatic digestion was performed in a mixture of one part Dulbecco's modified Eagle's medium/Ham's F12-solved papain $(0.5 \mathrm{mg} / \mathrm{ml}$; Sigma-Aldrich; Merck KGaA; Darmstadt, Germany) and one part buffer without calcium containing additional $32 \mathrm{mM}$ DTT and $0.5 \%$ bovine serum albumin (BSA; Sigma-Aldrich; Merck KGaA) for $30 \mathrm{~min}$ at $37^{\circ} \mathrm{C}$. Following centrifugation at room temperature at $300 \mathrm{x} \mathrm{g}$ for $10 \mathrm{~min}$, the supernatants were discarded and pulmonary artery pieces were digested with a buffer containing $0.75 \mathrm{mg} / \mathrm{ml}$ collagenase (Sigma-Aldrich; Merck KGaA) in the presence of $0.5 \% \mathrm{BSA}$ for $10 \mathrm{~min}$ at $37^{\circ} \mathrm{C}$. The enzyme was removed by centrifugation, and smooth muscle cells were resuspended with cell culture medium (Dulbecco's modified Eagle's medium/Ham's F12 1:1) supplemented with 10\% fetal calf serum (HyClone; GE Healthcare Life Sciences, Logan, UT, USA), 2 mM L-glutamine, 2.7 g/l D-glucose, 25 mM HEPES, $100 \mathrm{U} / \mathrm{ml}$ penicillin and $0.1 \mathrm{mg} / \mathrm{ml}$ streptomycin, and seeded on glass coverslips.

Cellular RNA isolation and reverse transcription-quantitative polymerase chain reaction $(R T-q P C R)$. A GeneJET ${ }^{\mathrm{TM}}$ RNA Purification kit (Fermentas; Thermo Fisher Scientific, Inc., Waltham, MA, USA) was utilized to isolate the total RNA from PASMCs. A Revert Aid ${ }^{\mathrm{TM}}$ First Strand cDNA synthesis kit (Fermentas; Thermo Fisher Scientific, Inc.) was utilized to synthesize the cDNA from the extracted RNA at $42^{\circ} \mathrm{C}$ for $60 \mathrm{~min}$ and $70^{\circ} \mathrm{C}$ for $10 \mathrm{~min}$. RT-qPCR was performed over 35 cycles at $94^{\circ} \mathrm{C}$ for $5 \mathrm{~min}$ to pre-denature, $94^{\circ} \mathrm{C}$ for $30 \mathrm{sec}$ to denature, $60^{\circ} \mathrm{C}$ for $30 \mathrm{sec}$ to anneal, and $72^{\circ} \mathrm{C}$ for $30 \mathrm{sec}$ for extension. The Applied Biosystems 7500 Sequence Detection System (ABI7500 SDS; Applied Biosystems; Thermo Fisher Scientific, Inc.) was utilized to perform RT-qPCR (PowerUp SYBR-Green; Thermo Fisher Scientific, Inc.), according to the manufacturer's protocol. Small nucleolar RNA (snoRNA) U6 was used as an internal control to normalize the expression of miR-16 and ADRB2 mRNA. The $2^{-\Delta \Delta \mathrm{Cq}}$ method, described elsewhere (23), was utilized to analyze the relative expression of miR-16 and ADRB2 mRNA. All reactions were performed in triplicate. The primers used in this study were as follows: miR-16 forward, 5'-GGGGTAGCAGCACGTAAAT-3' and reverse, 5'-TGTCGTGGAGTCGGCAATTG-3'; ADRB2 forward, 5'-AACTGGTTGGGCTATGTCAA-3' and reverse, 5'-GTTAGTGTCCTGTCAGGGAG-3'.

Serum RNA isolation and RT-qPCR. A Qiagen miRNeasy ${ }^{\circledR}$ kit (Qiagen $\mathrm{GmbH}$, Hilden, Germany) was utilized to isolate the total RNA from $100-\mu 1$ serum samples derived from all subjects, following the manufacturer's protocol. A NanoDrop ND-1000 spectrophotometer (Thermo Fisher Scientific, Inc., Wilmington, DE, USA) was utilized to measure the RNA 
concentration, and Revert Aid ${ }^{\mathrm{TM}}$ First Strand cDNA synthesis kit (Fermentas; Thermo Fisher Scientific, Inc.) was utilized to synthesize the cDNA from the extracted RNA. RT-qPCR was performed over 35 cycles at $94^{\circ} \mathrm{C}$ for $5 \mathrm{~min}$ to pre-denature, $94^{\circ} \mathrm{C}$ for $30 \mathrm{sec}$ to denature, $60^{\circ} \mathrm{C}$ for $30 \mathrm{sec}$ to anneal, and $72^{\circ} \mathrm{C}$ for $30 \mathrm{sec}$ for extension. ABI7500 SDS as utilized to performed RT-qPCR (PowerUp SYBR-Green; Thermo Fisher Scientific, Inc.), according to the manufacturer's protocol. snoRNA U6 was used as an internal control to normalize the expression of miR-16 and ADRB2 mRNA. The $2^{-\Delta \Delta \mathrm{Cq}}$ method was utilized to analyze the relative expression of miR-16 mRNA and ADRB2. All reactions were performed in triplicate. The primers used were as stated above.

miRNA target prediction. Targets mRNAs of miRNAs were predicted using miRanda (http://miranda.org.uk/). miRanda predicts the biological targets of miRNAs by searching for the presence of conserved 8 mer and 7 mer sites that match the seed region of each miRNA. Also identified are sites with mismatches in the seed region that are compensated by conserved 3' pairing. In mammals, predictions are ranked based on the predicted efficacy of targeting as calculated using the context+ scores of the site alignment. TargetScan (http://www. targetscan.org/vert_72/) Human considers matches to annotate human UTRs and their orthologs, as defined by UCSC whole-genome alignments (24). Conserved targeting was also detected within open reading frames.

Cell culture and transfection. Minimum essential medium (MEM; Invitrogen; Thermo Fisher Scientific, Inc,) supplemented with $10 \%$ fetal bovine serum (HyClone; GE Healthcare Life Sciences), 1,000 $\mu \mathrm{g} / \mathrm{ml}$ streptomycin sulfate and 1,000 U/ml penicillin G (Invitrogen; Thermo Fisher Scientific, Inc.), $20 \mathrm{mM} / \mathrm{L}$-glutamine and $1 \mathrm{mM}$ MEM non-essential amino acids was used to maintain the PASMCs under an atmosphere of $5 \% \mathrm{CO}_{2}$ at $37^{\circ} \mathrm{C}$. When the cells reached $30-50 \%$ confluence, Lipofectamine ${ }^{\circledR} 2000$ transfection reagent (Invitrogen; Thermo Fisher Scientific, Inc.) was used to transfect the PASMCs with miR-16 mimics (5'-AAAUGCACGACGAU-3') or negative control (5'-UUCUCCGAACGUGUCACGUTT-3') at 0, 25, 50 or $75 \mathrm{nM}$ for $48 \mathrm{~h}$ (Shanghai GenePharma Co., Ltd., Shanghai, China), following the manufacturer's protocol. All experiments were performed three times.

Luciferase assay. Normal human cDNA served as a template, and was used to amplify the ADRB2 3'UTR by site-directed mutagenesis. PCR was performed as described above. The PCR products were inserted into a pMIR-REPORT ${ }^{\mathrm{TM}}$ Expression Reporter Vector from Augusta University (Augusta, GA, USA), and DNA sequencing was performed to confirm the inserts. Cells were maintained in 48-well plates at a final density of $1 \times 10^{5}$ cells/well. Lipofectamine ${ }^{\circledR} 2000$ (Invitrogen; Thermo Fisher Scientific, Inc.) was used to co-transfect miR-16 mimics or negative control mimics and 3'UTR ADRB2 luciferase reporter constructs or pRL-CMV as an internal control for $48 \mathrm{~h}$. The dual luciferase reporter assay system (Promega Corporation, Madison, WI, USA) was used to measure the luciferase activity based on the introduction by the manufacturer by comparing with Renilla luciferase. Each test was carried out three times.
Table I. Demographic and clinical characteristics of the study groups.

\begin{tabular}{|c|c|c|c|}
\hline \multirow[b]{2}{*}{ Parameter } & \multicolumn{2}{|c|}{ Asthmatic patients $(n=72)$} & \multirow[b]{2}{*}{ P-value } \\
\hline & $\begin{array}{l}\text { Sensitive } \\
(n=52)\end{array}$ & $\begin{array}{l}\text { Resistant } \\
(\mathrm{n}=20)\end{array}$ & \\
\hline Age, years & $19.1 \pm 6.2$ & $18.9 \pm 7.9$ & 0.671 \\
\hline \multicolumn{4}{|l|}{ Sex, n (\%) } \\
\hline Male & $21(40.4)$ & $9(45.0)$ & \\
\hline Female & $31(59.6)$ & $11(55.0)$ & 0.722 \\
\hline \multicolumn{4}{|c|}{ Residence, n (\%) } \\
\hline Rural & $17(32.7)$ & $7(35.0)$ & \\
\hline Urban & $35(67.3)$ & $13(65.0)$ & 0.852 \\
\hline \multicolumn{4}{|c|}{$\begin{array}{l}\text { Family history of } \\
\text { asthma, n (\%) }\end{array}$} \\
\hline Negative & $15(28.8)$ & $6(30.0)$ & \\
\hline Positive & $37(71.2)$ & $14(70.0)$ & 0.924 \\
\hline FEV1 & $71.4 \pm 8.2$ & $72.5 \pm 6.7$ & 0.812 \\
\hline
\end{tabular}

FEV1, forced expiratory volume in $1 \mathrm{sec}$.

Western blot analysis. A radioimmunoprecipitation assay lysis buffer (Upstate Biotechnology, Inc., Lake Placid, NY, USA) with protease inhibitor cocktail (Sigma-Aldrich; Merck $\mathrm{KGaA}$ ) was utilized to lyse the cells $48 \mathrm{~h}$ post-transfection to detect the expression level of ADRB2 protein, in accordance with the manufacturer's protocol. The protein was quantified using the bicinchoninic acid method. SDS gradient gels of 4-20\% (Mini-PROTEAN TGX; Bio-Rad Laboratories, Inc., Hercules, CA, USA) were utilized to load equal amounts $(30 \mu \mathrm{g})$ of total protein, and gel electrophoresis was performed to separate the proteins, followed by transfer to polyvinylidene fluoride membranes (Immobilon-P; EMD Millipore, Billerica, MA, USA). The primary antibodies anti-ADRB2 at a dilution of 1:5,000 (cat. no. 8513; Cell Signaling Technology, Inc., Beverly, MA, USA) and monoclonal anti- $\beta$-actin at dilution of 1:10,000 (cat. no. sc-130301; Santa Cruz Biotechnology, Inc., Dallas, TX, USA) were utilized to treat the membrane at $4^{\circ} \mathrm{C}$ overnight, and horseradish peroxidase (HRP)-conjugated secondary anti-rabbit immunoglobulin $\mathrm{G}$ antibody at a dilution of 1:10,000 (cat. no. ab6721; Abcam, Cambridge, MA, USA) was used to treat the membrane for $60 \mathrm{~min}$ at room temperature. ImageJ software version 1.0 (National Institutes of Health, Bethesda, MD, USA) was used to visualize the bands. Each test was repeated in triplicate.

Statistical analysis. All data are presented as the mean \pm standard deviation. SPSS 15.0 software (SPSS, Inc., Chicago, IL, USA) was used for statistical analysis, and a Student's t-test, or one-way analysis of variance followed by a post hoc multiple comparison via the Bonferroni method, was performed to analyze the differences among groups. Receiver operating characteristic (ROC) curves were generated to evaluate the association between miR-16 and sensitivity. Pearson correlation analysis was used to evaluate the correlation between 


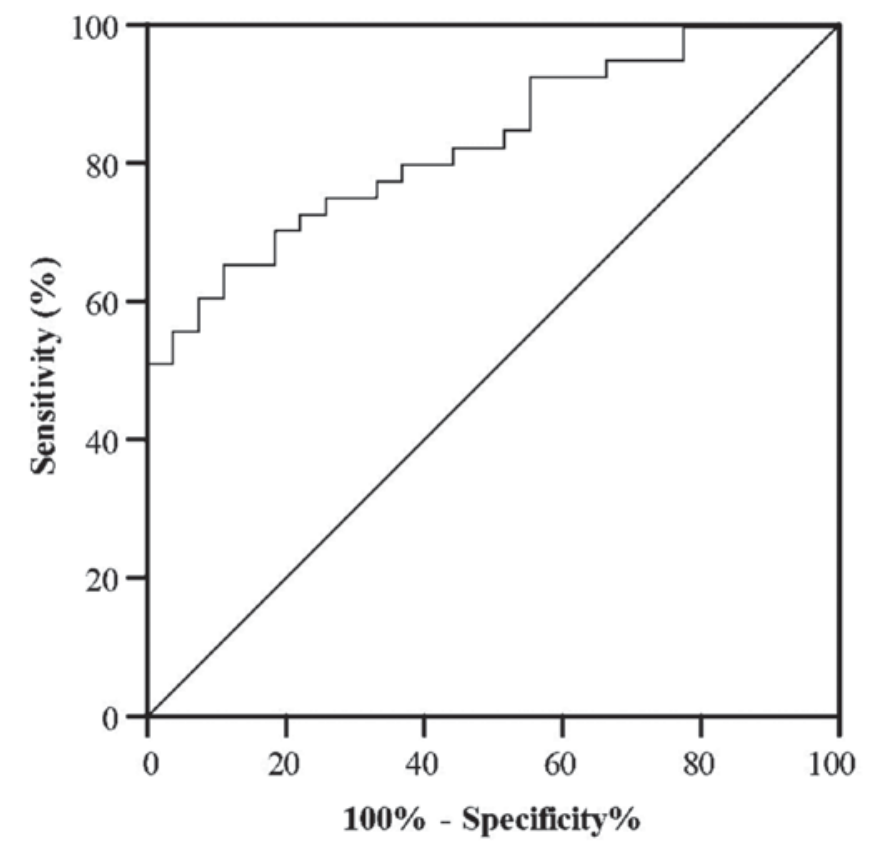

Figure 1. Receiver operating characteristic curve analysis of serum microRNA-16 in discriminating between patients who are sensitive and resistant to salmeterol.

miR-16 and forced expiratory volume in $1 \mathrm{sec}$ (FEV1). $\mathrm{P}<0.05$ was considered to indicate a statistically significant difference.

\section{Results}

Clinical and demographic characteristics of subjects. A total of 72 volunteers diagnosed with asthma were enrolled in the present study, of whom 52 participants were identified to be sensitive to salmeterol (sensitive group) and 20 participants were identified to be resistant to salmeterol (resistant group). Information on the subjects, including age, sex, residence, family history of asthma and FEV1 was collected and is presented in Table I. FEV1 was not significantly different between the sensitive and resistant groups.

ROC curve analysis. A ROC curve was generated to detect the optimal sensitivity and specificity threshold values of miR-16 between participants sensitive and resistant to salmeterol. It was observed that the serum miR-16 level may function as a biomarker to predict the response to salmeterol therapy, with an area under the curve (AUC) value of 0.99, and was robust in distinguishing between patients with asthma who were sensitive or resistant to salmeterol. The cut off value was $<2.8$. The specificity and sensitivity cut off values of miR-16 to verify a subject with asthma as being sensitive or resistant to salmeterol were 96.2 and $88.4 \%$, respectively (Fig. 1).

Correlation between serum miR-16 and FEV1. In order to demonstrate the correlation between the miR-16 expression level and FEV1, Pearson correlation analysis was performed. As presented in Fig. 2, miR-16 expression displayed a significant negative correlation with FEV1.

$A D R B 2$ is a direct target of miR-16. To examine the underlying molecular mechanism of the association between miR-16

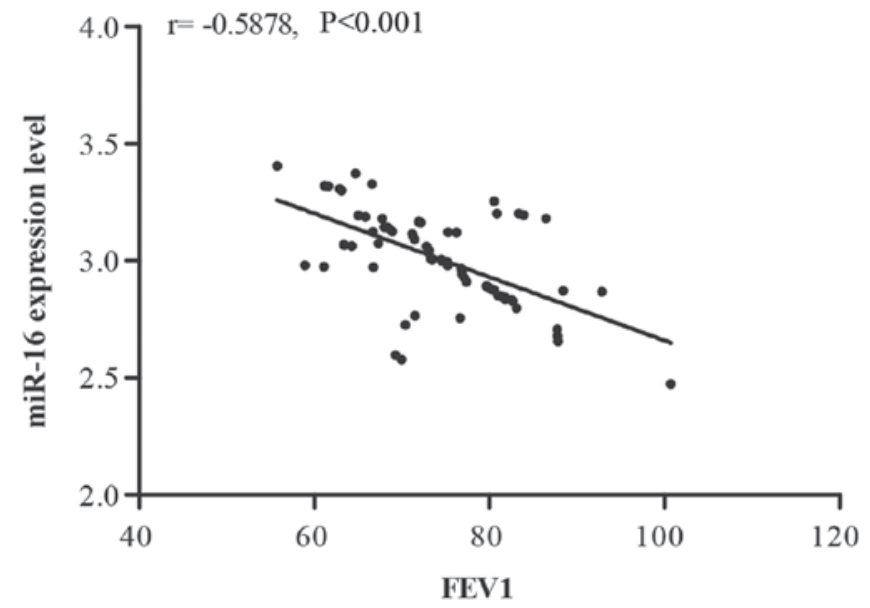

Figure 2. Analysis of the correlation between serum miR-16 and FEV1. miR, microRNA; FEV1, forced expiratory volume in $1 \mathrm{sec}$.

expression and response to therapy in asthma, as presented in Fig. 3, the association between miR-16 and its target genes was analyzed using bioinformatics analysis with miRanda (version 2010). It was identified that ADRB2 had a predicted binding site for miR-16, and the 'seed sequence' located on the ADRB2 3'UTR was highly conserved among species, indicating that this seed sequence may serve an important function.

Furthermore, to verify that miR-16 regulates the expression of ADRB2 by binding to its 3'UTR, the ADRB2 3'UTR fragment containing the miR-16 putative binding site was amplified by PCR, and site-directed mutagenesis was performed to mutate the binding site of miR-16 located within ADRB2 3'UTR to eradicate miR-16 binding to ADRB2 mRNA. The wild-type and mutant ADRB2 3'UTRs were inserted into luciferase reporter vectors to obtain pMIR-(wildtype or mutant) ADRB2-3'UTR constructs. PASMCs were maintained in 48-well plates, and co-transfected with the constructs and different doses of miR-16 mimic $(0,25,50$ and $75 \mathrm{nM}$ ). RT-qPCR revealed that miR-16 expression was gradually increased following miR-16 mimic transfection, in a dose-dependent manner (Fig. 4A). Luciferase activity was detected $48 \mathrm{~h}$ post-transfection, as presented in Fig. 4B, $25 \mathrm{nM}$ miR-16 mimic exerted an inhibitory effect on the luciferase activity of the wild-type ADRB2 3'UTR; the inhibitory effect of $50 \mathrm{nM}$ miR-16 mimic was stronger, and that of $75 \mathrm{nM}$ miR-16 mimic was the strongest. The luciferase activity of the mutant ADRB2 3'UTR in cells was similar following treatment with $0,25,50$ or $75 \mathrm{nM}$ miR-16 mimic (Fig. 4C). These data collectively suggested that miR-16 was a direct regulator of ADRB2, and negatively regulated the expression of ADRB2 in a dose-dependent manner.

Inhibition of ADRB2 expression via miR-16 transfection. To further confirm the regulatory role of miR-16 in the control of ADRB2 expression, gain-of-function analysis was performed in the PASMCs by transfecting the cells with different doses of miR-16 mimic (0, 25, 50 and $75 \mathrm{nM})$. RT-qPCR and western blotting were performed to examine the expression of ADRB2 in the different treatment groups. As presented in Fig. 5, miR-16 mimic, in a concentration-dependent manner, suppressed the 


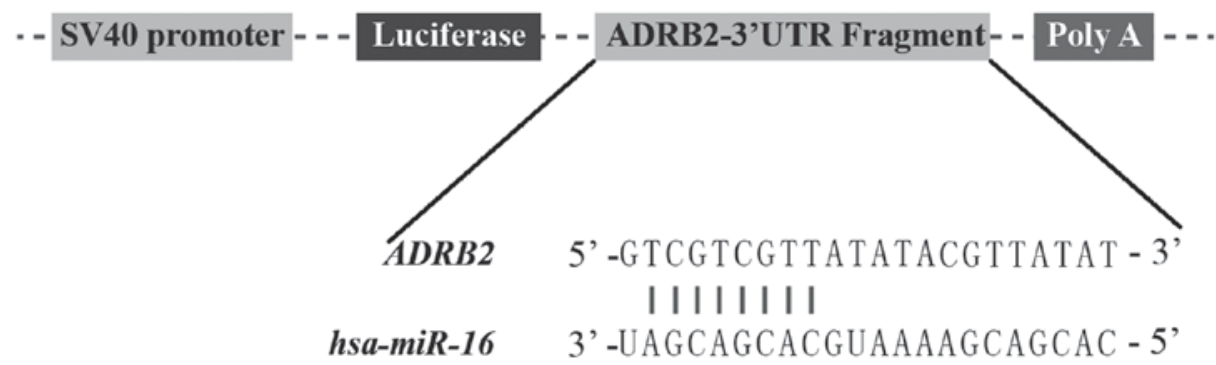

Figure 3. Schematic representation of the target sequence in the 3'UTR of ADRB2 and miR-16. UTR, untranslated region; ADRB2, adrenoreceptor $\beta$-2; miR, microRNA.
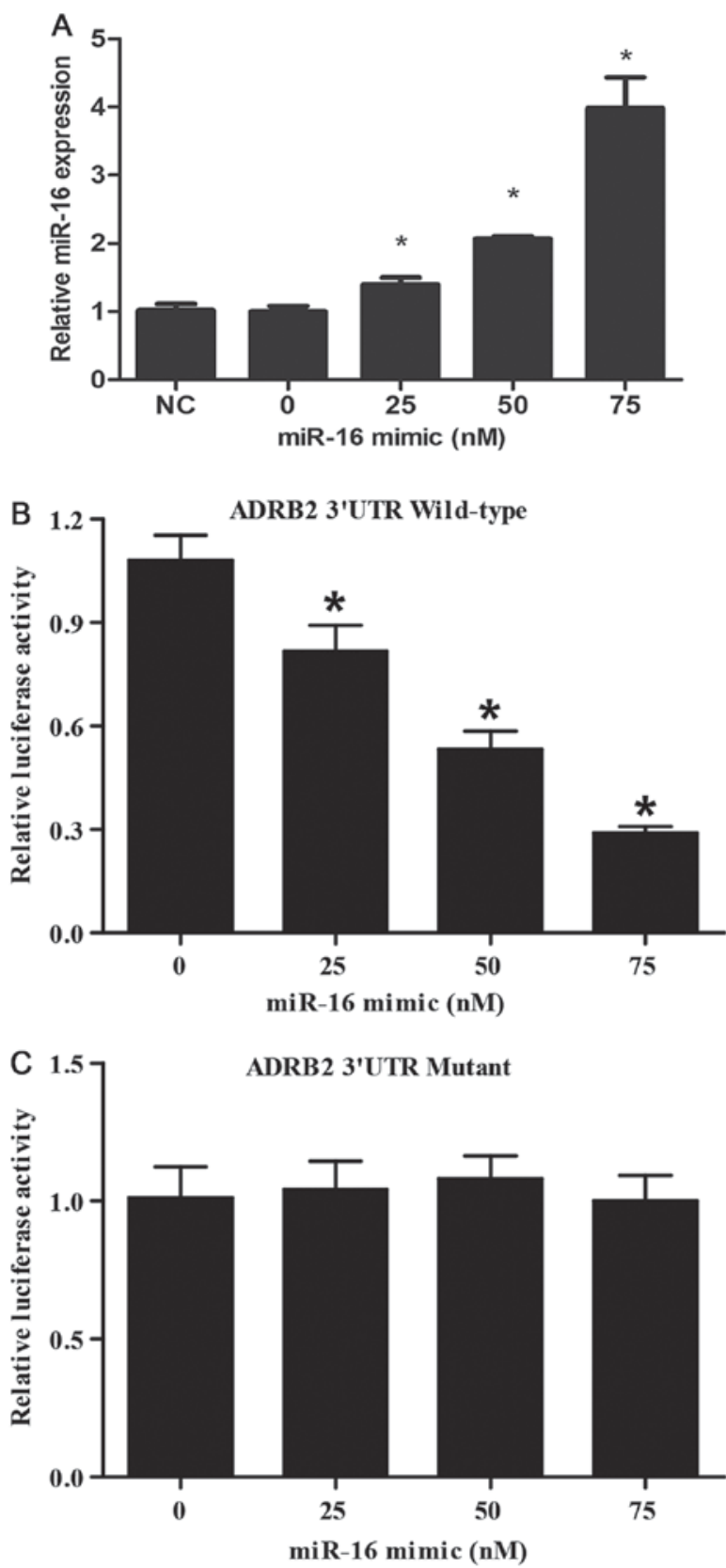

Figure 4. miR-16 binding with the 3'UTR of ADRB2 gene. (A) Reverse transcription-quantitative polymerase chain reaction analysis of miR-16 expression in cells transfected with different doses of miR-16 mimics. (B) Luciferase analysis of the wild-type ADRB2 3'UTR in cells transfected with different doses of miR-16 mimic. (C) Luciferase analysis of the mutant ADRB2 3'UTR in cells transfected with different dose of miR-16 mimic. ${ }^{*} \mathrm{P}<0.05$ vs. $0 \mathrm{nM}$ miR-16 group. miR, microRNA; UTR, untranslated region; ADRB2, adrenoreceptor $\beta-2$.

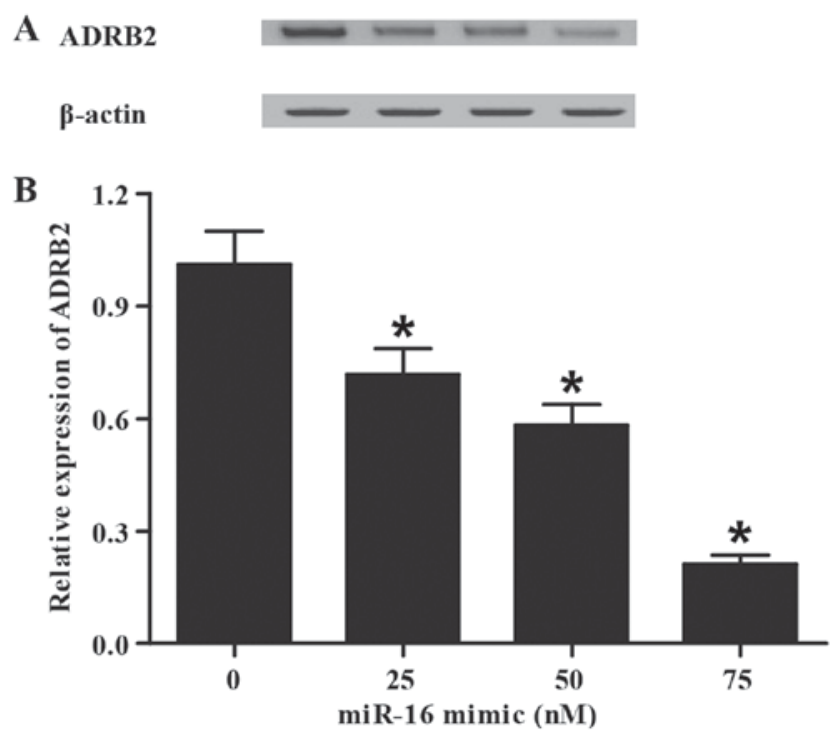

Figure 5. miR-16 transfection inhibits ADRB2 expression. (A) Western blot analysis of ADRB2 protein expression in cells transfected with different doses of miR-16 mimic. (B) Reverse transcription-quantitative polymerase chain reaction detection of ADRB2 mRNA level in cells transfected by different dose of miR-16 mimics. ${ }^{*} \mathrm{P}<0.05$ vs. $0 \mathrm{nM}$ miR-16 group. miR, microRNA; ADRB2, adrenoreceptor $\beta-2$.

protein (Fig. 5A) and mRNA (Fig. 5B) expression of ADRB2, indicating that ADRB2 was a target of miR-16, and that miR-16 inhibited the expression of ADRB2.

\section{Discussion}

Asthma causes persistent inflammation of the airways, and is characterized by shortness of breath, chest tightness, and intermittent episodes of wheezing and airway hyperresponsiveness. A previous study revealed that a range of miRNAs are increased when responding to inflammatory stimuli in human epithelial cell lines and in mouse models of inflammation (25). The application of drugs, including corticosteroids and $\beta 2$ agonists, by patients may also trigger interference with the expression of miRNAs that may be associated with asthmatic pathogenesis (26); asthmatics who had never undergone corticosteroid treatment for their asthma were previously assessed, and the expression of 227 miRNAs that represent a large majority of those demonstrated to be either uniquely generated, or those contributing to a large majority of the variations in miRNA profiles between tissues and cell lineages, was determined (27). Improvements in bronchial hyperresponsiveness may be 
largely due to the anti-inflammatory role of corticosteroids. No alteration in the expression of miRNAs was discovered following budesonide therapy, regardless of the fact that certain of the abundantly expressed miRNAs included binding sites for the nuclear factor- $\kappa \mathrm{B}$ transcription factor. It is likely that no action is exerted by budesonide upon basal miRNA expression, considering the absence of differentially expressed miRNAs in mild asthmatics (26).

miR-16 is a member of the miR-15/miR-16 cluster that is present on the noncoding gene deleted in lymphocytic leukemia 2 (28). Verified targets of miR-16 include numerous genes associated with the modulation of cell-cycle progression, including cyclin E and cyclin D1 among others (29-31). miR-16 has been demonstrated to be commonly decreased in persistent lymphocytic leukemia (32). However, the action of miR-16 in solid malignant tumors remains largely unknown. For example, miR-15a and miR-16 are markedly reduced in advanced prostate cancer, while the expression of Wnt family member 3A, cyclin D1 and BCL2, apoptosis regulator is consistently increased (29). This investigation demonstrated that the reconstruction of miR-16 in prostate cancer cells leads to apoptosis, growth arrest, and marked regression of prostate tumor xenografts in experimental models (29). miR-16 overexpression was demonstrated to render MCF-7 human breast cancer cells sensitive to the chemotherapeutic agent doxorubicin, and to inhibit the growth and self-renewal of mammary tumor stem cells in mice (33). In the present study, 72 volunteers diagnosed with asthma were recruited, and they were divided into two groups: Asthmatic participants sensitive to salmeterol $(n=52)$ and asthmatic participants resistant to salmeterol $(n=20)$. It was found that FEV1 was not significantly different between the sensitive and resistant groups. ROC curve analysis was performed to determine the optimal sensitivity and specificity threshold values of miR-16 between the sensitive and resistant groups, and it was revealed that the serum miR-16 level may function as a biomarker to predict responses to salmeterol therapy, with an AUC value of 0.99. In addition, Pearson correlation analysis was performed between miR-16 expression and FEV1, and it was observed that miR-16 expression displayed a significant negative correlation with FEV1. The observed negative correlation between miR-16 and FEV1 indicated that miR-16 may function as a negative regulator of ADRB2; the expression level of ADRB2 is positively correlated with lung functional indices, including FEV1 (34), thus it is not unexpected that miR-16 is negatively correlated with FEV1.

As a member of the $\mathrm{G}$ protein-coupled receptor family, ADRB2 is highly expressed on bronchial smooth muscle cells, and has specific binding sites for and is stimulated by a group of ligands termed catecholamines, particularly epinephrine (35). The stimulation of ADRB2 may lead to dilation of the small airways, and thus ADRB2 agonists are applied as a first-line bronchodilator treatment in asthma (36). ADRB2, which has a direct role in the effect of $\beta-1$ adrenergic bronchodilators, is encoded by an intronless gene present on chromosome 5q31-32 (37). It has been demonstrated that ADRB2 variants are associated with treatment response, asthma severity and airway hypersensitivity (38).

The most frequently prescribed and applied inhaled asthma drugs are ADRB2 agonists (38). Their effectiveness partially relies on the structure, density and conformation of ADRB2 on the cell surface, and their molecular consistency and functions. The modulation/expression of ADRB2 is altered by a range of single nucleotide polymorphisms in the promoter, coding and the 3'UTR domains (37). ADRB2+46*G (Gly16) leads to receptor downregulation triggered by agonists, while ADRB2 $+79 * \mathrm{G}$ (Glu27) is notably resistant (37). The receptor binding affinity is altered by ADRB2+491*T (Ile164), with decreased activation in vitro and reduced in vivo sensitivity to terbutaline in individuals with cardiac failure and healthy people $(39,40)$. In the present study, computational analysis was performed, and it was observed that ADRB2 had a predicted binding site for miR-16, located in the highly conserved 3'UTR. A luciferase reporter assay was conducted to test the above hypothesis, and it was revealed that $25 \mathrm{nM}$ miR-16 mimic suppressed the luciferase activity of wild-type ADRB2 3'UTR; the inhibitory effect on the luciferase activity of the wild-type ADRB2 3'UTR was stronger with $50 \mathrm{nM}$ miR-16 mimic, and strongest with $75 \mathrm{nM}$ miR-16 mimic, whereas the luciferase activity of the mutant ADRB2 3'UTR in cells was similar following treatment with $0,25,50$ or $75 \mathrm{nM}$ miR-16 mimic. Finally, western blotting and RT-qPCR were performed to confirm the regulatory association between miR-16 and ADRB2, and it was observed that miR-16 mimic suppressed the ADRB2 protein and mRNA expression levels in a concentration-dependent manner.

The focus of the present study was the response medical treatment in patients with asthma. In addition to the involvement of miR-16 in the control of the response to treatment, miR-16 has also been reported to be differentially expressed in airway smooth muscle cells collected from subjects with asthma, and was considered to be the hub of the miRNA regulatory network which is involved in the pathogenesis of asthma (41-44).

The present results identified that miR-16 may be used as a predictive biomarker of response to therapy in asthma.

\section{Acknowledgements}

Not applicable.

\section{Funding}

No funding was received.

\section{Availability of data and materials}

The datasets used and/or analyzed during the current study are available from the corresponding author on reasonable request.

\section{Authors' contributions}

BY and LY contributed to the conception and design of this study. BY, CL, LT and TX performed the statistical analysis and drafted the manuscript. BY, CL and LT drafted the manuscript. BY, LY and TX critically reviewed the manuscript and supervised the whole study process.

\section{Ethics approval and consent to participate}

The institutional Ethics and Research Committees of Liaocheng People's Hospital (Liaocheng, China) approved the protocol of the present study. All patients provided informed consent. 


\section{Patient consent for publication}

All patients signed informed consent forms for publication.

\section{Competing interests}

The authors declare that they have no competing interests.

\section{References}

1. Burgess JA, Matheson MC, Gurrin LC, Byrnes GB, Adams KS, Wharton CL, Giles GG, Jenkins MA, Hopper JL, Abramson MJ, et al: Factors influencing asthma remission: A longitudinal study from childhood to middle age. Thorax 66: 508-513, 2011.

2. Pavord ID: Non-eosinophilic asthma and the innate immune response. Thorax 62: 193-194, 2007.

3. Donohue JF, Herje N, Crater G and Rickard K: Characterization of airway inflammation in patients with COPD using fractional exhaled nitric oxide levels: A pilot study. Int J Chron Obstruct Pulmon Dis 9: 745-751, 2014.

4. Leung DY and Bloom JW: Update on glucocorticoid action and resistance. J Allergy Clin Immunol 111: 3-22; quiz 23, 2003.

5. Malmstrom K, Rodriguez-Gomez G, Guerra J, Villaran C, Piñeiro A, Wei LX, Seidenberg BC and Reiss TF: Oral montelukast, inhaled beclomethasone, and placebo for chronic asthma A randomized, controlled trial. Montelukast/Beclomethasone Study Group. Ann Intern Med 130: 487-495, 1999.

6. Leung DY, Martin RJ, Szefler SJ, Sher ER, Ying S, Kay AB and Hamid Q: Dysregulation of interleukin 4, interleukin 5, and interferon gamma gene expression in steroid-resistant asthma J Exp Med 181: 33-40, 1995

7. Drazen JM: Asthma: The paradox of heterogeneity. J Allergy Clin Immunol 129: 1200-1201, 2012.

8. Yang M, Kumar RK, Hansbro PM and Foster PS: Emerging roles of pulmonary macrophages in driving the development of severe asthma. J Leukoc Biol 91: 557-569, 2012.

9. Kunos G and Szentivanyi M: Evidence favouring the existence of a single adrenergic receptor. Nature 217: 1077-1078, 1968.

10. Shelhamer JH, Marom Z and Kaliner M: Abnormal beta-adrenergic responsiveness in allergic subjects. II. The role of selective beta 2-adrenergic hyporeactivity. J Allergy Clin Immunol 71 : 57-61, 1983.

11. Marsh DG, Neely JD, Breazeale DR, Ghosh B, Freidhoff LR, Ehrlich-Kautzky E, Schou C, Krishnaswamy G and Beaty TH: Linkage analysis of IL4 and other chromosome 5q31.1 markers and total serum immunoglobulin E concentrations. Science 264 1152-1156, 1994.

12. Postma DS, Bleecker ER, Amelung PJ, Holroyd KJ, Xu J Panhuysen CI, Meyers DA and Levitt RC: Genetic susceptibility to asthma-bronchial hyperresponsiveness coinherited with a major gene for atopy. N Engl J Med 333: 894-900, 1995.

13. Inui M, Martello G and Piccolo S: MicroRNA control of signal transduction. Nat Rev Mol Cell Biol 11: 252-263, 2010.

14. Chen CZ, Li L, Lodish HF and Bartel DP: MicroRNAs modulate hematopoietic lineage differentiation. Science 303: 83-86, 2004.

15. Ariel D and Upadhyay D: The role and regulation of microRNAs in asthma. Curr Opin Allergy Clin Immunol 12: 49-52, 2012.

16. Jardim MJ, Dailey L, Silbajoris R and Diaz-Sanchez D: Distinct microRNA expression in human airway cells of asthmatic donors identifies a novel asthma-associated gene. Am J Respir Cell Mol Biol 47: 536-542, 2012

17. Solberg OD, Ostrin EJ, Love MI, Peng JC, Bhakta NR, Hou L, Nguyen C, Solon M, Nguyen C, Barczak AJ, et al: Airway epithelial miRNA expression is altered in asthma. Am J Respir Crit Care Med 186: 965-974, 2012.

18. Burger H, van Leen RW, Dorssers LC, Persoon NL, Lemson PJ and Wagemaker G: Species specificity of human interleukin-3 demonstrated by cloning and expression of the homologous rhesus monkey (Macaca mulatta) gene. Blood 76: 2229-2234, 1990.

19. Zhang YY, Zhong M, Zhang MY and Lv K: Expression and clinical significance of miR-155 in peripheral blood CD4(+); $\mathrm{T}$ cells of patients with allergic asthma. Xi Bao Yu Fen Zi Mian Yi Xue Za Zhi 28: 540-543, 2012 (In Chinese)
20. Panganiban RP, Wang Y, Howrylak J, Chinchilli VM, Craig TJ, August A and Ishmael FT: Circulating microRNAs as biomarkers in patients with allergic rhinitis and asthma. J Allergy Clin Immunol 137: 1423-1432, 2016.

21. Gimenez LE, Baameur F, Vayttaden SJ and Clark RB: Salmeterol efficacy and bias in the activation and kinase-mediated desensitization of $\beta 2$-adrenergic receptors. Mol Pharmacol 87: 954-964, 2015.

22. Berger WE and Noonan MJ: Treatment of persistent asthma with Symbicort (budesonide/formoterol inhalation aerosol): An inhaled corticosteroid and long-acting beta2-adrenergic agonist in one pressurized metered-dose inhaler. J Asthma 47: 447-459, 2010.

23. Livak KJ and Schmittgen TD: Analysis of relative gene expression data using real-time quantitative PCR and the 2(-Delta Delta C(T)) method. Methods 25: 402-408, 2011.

24. Kuhn RM, Haussler D and Kent WJ: The UCSC genome browser and associated tools. Brief Bioinform 14: 144-161, 2013.

25. Perry MM, Moschos SA, Williams AE, Shepherd NJ, LarnerSvensson HM and Lindsay MA: Rapid changes in microRNA-146a expression negatively regulate the IL-1beta-induced inflammatory response in human lung alveolar epithelial cells. J Immunol 180: 5689-5698, 2008.

26. Mi S, Zhang J, Zhang W and Huang RS: Circulating microRNAs as biomarkers for inflammatory diseases. Microrna 2: 63-71, 2013.

27. Landgraf P, Rusu M, Sheridan R, Sewer A, Iovino N, Aravin A, Pfeffer S, Rice A, Kamphorst AO, Landthaler M, et al: A mammalian microRNA expression atlas based on small RNA library sequencing. Cell 129: 1401-1414, 2007.

28. Lerner M, Harada M, Lovén J, Castro J, Davis Z, Oscier D, Henriksson M, Sangfelt O, Grandér D and Corcoran MM: DLEU2, frequently deleted in malignancy, functions as a critical host gene of the cell cycle inhibitory microRNAs miR-15a and miR-16-1. Exp Cell Res 315: 2941-2952, 2009.

29. Bonci D, Coppola V, Musumeci M, Addario A, Giuffrida R, Memeo L, D'Urso L, Pagliuca A, Biffoni M, Labbaye C, et al: The miR-15a-miR-16-1 cluster controls prostate cancer by targeting multiple oncogenic activities. Nat Med 14: 1271-1277, 2008.

30. Wang F, Fu XD, Zhou Y and Zhang Y: Down-regulation of the cyclin E1 oncogene expression by microRNA-16-1 induces cell cycle arrest in human cancer cells. BMB Rep 42: 725-730, 2009.

31. Chung EY, Dews M, Cozma D, Yu D, Wentzel EA, Chang TC, Schelter JM, Cleary MA, Mendell JT and Thomas-Tikhonenko A: c-Myb oncoprotein is an essential target of the dleu2 tumor suppressor microRNA cluster. Cancer Biol Ther 7: 1758-1764, 2008.

32. Calin GA, Dumitru CD, Shimizu M, Bichi R, Zupo S, Noch E, Aldler H, Rattan S, Keating M, Rai K, et al: Frequent deletions and down-regulation of micro- RNA genes miR15 and miR16 at $13 q 14$ in chronic lymphocytic leukemia. Proc Natl Acad Sci USA 99: 15524-15529, 2012.

33. Zhang X, Wan G, Mlotshwa S, Vance V, Berger FG, Chen H and Lu X: Oncogenic Wip1 phosphatase is inhibited by miR-16 in the DNA damage signaling pathway. Cancer Res 70: 7176-7186, 2010.

34. Kim WJ, Oh YM, Sung J, Kim TH, Huh JW, Jung H, Lee JH, Kim EK, Lee JH, Lee SM, et al: Lung function response to 12-week treatment with combined inhalation of long-acting beta 2 agonist and glucocorticoid according to ADRB2 polymorphism in patients with chronic obstructive pulmonary disease. Lung 186: 381-386, 2008.

35. Litonjua AA, Gong L, Duan QL, Shin J, Moore MJ, Weiss ST, Johnson JA, Klein TE and Altman RB: Very important pharmacogene summary ADRB2. Pharmacogenet Genomics 20: 64-69, 2010.

36. Pignatti PF: Trends in pharmacogenomics of drugs used in the treatment of asthma. Pharmacol Res 49: 343-349, 2004.

37. Brodde $\mathrm{OE}$ and Leineweber K: Beta2-adrenoceptor gene polymorphisms. Pharmacogenet Genomics 15: 267-275, 2005.

38. Contopoulos-Ioannidis DG, Manoli EN and Ioannidis JP: Meta-analysis of the association of beta2-adrenergic receptor polymorphisms with asthma phenotypes. J Allergy Clin Immunol 115: 963-972, 2005.

39. Ortega VE, Hawkins GA, Moore WC, Hastie AT, Ampleford EJ, Busse WW, Castro M, Chardon D, Erzurum SC, Israel E, et al: Effect of rare variants in ADRB2 on risk of severe exacerbations and symptom control during longacting $\beta$ agonist treatment in a multiethnic asthma population: A genetic study. Lancet Respir Med 2: 204-213, 2014 
40. Hawkins GA, Tantisira K, Meyers DA, Ampleford EJ, Moore WC, Klanderman B, Liggett SB, Peters SP, Weiss ST and Bleecker ER: Sequence, haplotype, and association analysis of ADRbeta2 in a multiethnic asthma case-control study. Am J Respir Crit Care Med 174: 1101-1109, 2006.

41. Green SA, Turki J, Innis M and Liggett SB: Amino-terminal polymorphisms of the human beta 2 -adrenergic receptor impart distinct agonist-promoted regulatory properties. Biochemistry 33: 9414-9419, 1994.

42. Green SA, Cole G, Jacinto M, Innis M and Liggett SB: A polymorphism of the human beta 2 -adrenergic receptor within the fourth transmembrane domain alters ligand binding and functional properties of the receptor. J Biol Chem 268: 23116-23121, 1993.
43. Barbato E, Penicka M, Delrue L, Van Durme F, De Bruyne B, Goethals M, Wijns W, Vanderheyden M and Bartunek J: Thr164Ile polymorphism of beta2-adrenergic receptor negatively modulates cardiac contractility: Implications for prognosis in patients with idiopathic dilated cardiomyopathy. Heart 93: 856-861, 2007.

44. Davis JS, Sun M, Kho AT, Moore KG, Sylvia JM, Weiss ST, Lu Q and Tantisira KG: Circulating microRNAs and association with methacholine PC20 in the Childhood Asthma Management Program (CAMP) cohort. PLoS One 12: e0180329, 2017.

(i) (2) This work is licensed under a Creative Commons

cc) International (CC BY-NC-ND 4.0) License. 